\title{
Guía PRADO. Sostenibilizar el currículo de la Educación Secundaria
}

\author{
Ma José Díaz González \\ Cuerpo de Profesores de Educación Secundaria de la Comunidad de Madrid \\ m.diaz2@educa.madrid.org \\ ORCID: https://orcid.org/0000-0002-6210-7546
}

PRADO guide. To make the curriculum of Secondary Education sustainable

\begin{abstract}
Para citar la obra reseñada: Díaz González, M. J. (2020). Reseña de Murga-Menoyo, Mạ A. y BautistaCerro, Ma J. (Editoras) (2019). Guía PRADO. Sostenibilizar el currículo de la Educación Secundaria. Madrid: UNED, 422 págs. doi: https://doi.org/10.5944/catedra.eads.501120. Revista de Educación $\begin{array}{lllll}\text { Ambiental } & y & \text { Sostenibilidad } & 2(1), & 1401 .\end{array}$ 10.25267/Rev_educ_ambient_sostenibilidad.2020.v2.i1.1401
\end{abstract}

El pasado mes de diciembre de 2020 asistimos en Madrid a la COP25, encuentro en el que las altas esferas políticas internacionales, la comunidad científica y los distintos movimientos sociales confirmaron algo que ya sabíamos: nos encontramos inmersos en una situación de emergencia climática. Ésta es la agudización más clara de una crisis ecológica y social a escala planetaria ya pronosticada desde hace años por multitud de expertos/as.

Sin embargo, no todo son malas noticias. Existen fuertes esfuerzos institucionales y de la ciudadanía para mejorar la sostenibilidad de nuestros territorios. Naciones Unidas lleva décadas trabajando en este camino y en el año 2015 realizó un nuevo llamamiento firmado por todos sus estados miembro para poner fin a la pobreza, proteger el planeta y garantizar que todas las personas gocen de paz y prosperidad: son los 17 Objetivos de Desarrollo Sostenible (ODS) ligados a la Agenda 2030. Avanzar hacia ellos es crucial en tiempos de gran complejidad e incertidumbre, ¿pero qué papel puede realizar la educación en este camino?

La respuesta a esta amplia pregunta no es sencilla. En las últimas décadas han surgido gran variedad de iniciativas (desde actuaciones individuales a otras colectivas, organizadas o no en red, con una coordinación dispar, mejorando diversas capacidades para transformar realidades, vertebrar el territorio o manejar diferentes escalas espaciales). El objetivo siempre es común, buscar escenarios más sostenibles, pero su coordinación e integración en la Agenda 2030 es una asignatura aún pendiente.

Después de esta amplia introducción, es interesante presentar una iniciativa que busca superar estas dificultades: la Guía PRADO (como acrónimo de las siglas que dan nombre al proyecto de investigación cuyos resultados han nutrido su redacción). Esta guía se plantea como un recurso para que cualquier persona ligada a la educación formal pueda realizar de manera fácil y rigurosa un acercamiento a los diecisiete retos recogidos en los ODS. Para ello, sus autoras han realizado una revisión de cada objetivo, profundizando en seis aspectos:

1. Presentarnos la problemática que contextualiza cada desafío con datos clave de fuentes solventes, así como recordarnos cuáles son las metas a conseguir en 
el cumplimiento de dicho objetivo asociado a la Agenda 2030 y sus indicadores de logro.

2. Desgranar los objetivos educativos (categorizados en socio-emocionales, conductuales y cognitivos) que se deben trabajar para contribuir al ODS seleccionado.

3. Sugerir una batería de contenidos a trabajar en el aula en un contexto a priori formal (aunque adaptable a la educación no formal).

4. Enumerar diferentes enfoques y métodos de aprendizaje a través de la sugerencia de numerosas actividades para trabajar dichos contenidos desde diversas estrategias didácticas: cooperativas, analíticas, reflexivas, participativas, etc.

5. Recoger en un banco de recursos una amplia revisión de fuentes primarias de información fiables y rigurosas así como ofrecer un glosario donde aparecen los principales conceptos ligados a cada ODS.

6. Vincular el ODS trabajado con las materias que lo recogen como contenido a trabajar en el currículo oficial de Educación Secundaria Obligatoria y Bachillerato marcado por el desarrollo legislativo de la LOMCE (pudiéndose adaptar al marco normativo de cada autonomía).

A través de todos estos recursos se busca facilitar el trabajo en el aula de las principales competencias clave para la sostenibilidad que marca la UNESCO. Esta guía las plantea como una oportunidad para que con su adquisición la ciudadanía logre mejorar su "saber, saber hacer y saber valorar" en un mundo cambiante e incierto.

El documento presenta dichas competencias como: i. desarrollar el pensamiento sistémico para relacionar los diferentes aspectos o factores de la realidad, ii. analizar de forma crítica las situaciones a las que nos enfrentamos (sus debilidades y fortalezas), iii. tomar decisiones de forma colaborativa o participar activamente hacia un compromiso común, y iv. asumir la responsabilidad con las generaciones presentes y futuras. Adquiriéndolas, la población se dotará de herramientas para enfrentarse a los retos que ya nos marca la crisis social y ecológica en la que nos encontramos inmersos.

Esta guía, como bien califican sus autoras (quince de las dieciséis personas que firman este texto son mujeres), es una obra coral, resultado de un proyecto de investigación (EDU-2015-66591-R) financiado por el Ministerio de Economía y Competitividad. En él han participado reconocidas investigadoras de tres instituciones: la Universidad Nacional de Educación a Distancia (UNED), la Universidad Complutense de Madrid y la Universidad de Valencia.

El esfuerzo de todas las autoras ha tenido un mismo objetivo: lograr resultados que sirvan para dar un poco de luz a los procesos de sostenibilización curricular y facilitar la integración de los principios y valores de la sostenibilidad en la práctica docente cotidiana del profesorado. La finalidad es alcanzar entre todos los retos de la Agenda 2030. 